\title{
Approaches to Evaluation of Environmental and Economic Damage to the Kuzbass Agglomeration Caused by Coal Mining Industry Development
}

\author{
Piotr Kosinskiy ${ }^{1}$, Vladimir Merkuriev ${ }^{1}$, and Aleksey Medvedev ${ }^{2}$ \\ ${ }^{1}$ T.F. Gorbachev Kuzbass State Technical University, Kemerovo, Russian Federation \\ ${ }^{2}$ Kemerovo Institute (branch) of Plekhanov Russian University of Economics, Kemerovo, Russian \\ Federation
}

\begin{abstract}
The article is devoted to the study of coal mining industry problems in a region and environmental and economic damage caused by its activities. It is found that the intensive development of coal mining industry is accompanied by negative environmental consequences associated with the impact on social and economic indicators of a region and the quality of life of the population. The methodology for analysis and evaluation of environmental and economic damage to a regional economy based on the loss of gross regional product (GRP) and associated with the loss of working time due to the incidence of the population, determined by the level of environmental pollution, was developed. The developed methodology solves the problem of evaluating the impact of environmental components not only on environmental and economic damage, characterized by GRP losses, but also on the quality of life of the population. In addition, the optimization nature of the presented model allows finding the economic potential of producers and the objective efficiency of enterprises, which will make it possible to compensate for damage caused by environmental pollution that is adequate to the negative consequences of their activities.
\end{abstract}

\section{Introduction}

The modern development of economy is characterized by high rates of coal mining industry development, contributing to environmental impairment in some regions of the country. The focus on traditional GRP growth indicators, income, welfare, and its negative environmental consequences are becoming the object of close attention of scientists and doers.

The present-day situation shows a certain inconsistency in the evaluation of the use of natural resources and their losses, the impact, in this regard, on the environment, environmental and economic damage to the economy of the country and its individual regions. 
The underestimation of environmental and economic damage leads to a distortion of economic development indicators, which is fraught with the risk of an inefficient choice of social and economic development lines in general.

The lack of perfect methods for evaluating environmental and economic damage to the economy does not allow evaluating the consequences of coal mining industry development with a high degree of confidence and providing the rationale for introducing the environmental component into the context of social and economic development aimed at improving the quality of life and human well-being. This is especially important for the regions in which coal mining, metallurgical, chemical industries of the economy are prominent, which entails the presence of significant areas of disturbed land. These regions of the Siberian Federal District, which have a raw material orientation, include the Kemerovo region.

In the region, more than half of GRP is generated by coal mining industry, which is a leading branch of the regional economy. Therefore, the development of the methodology for evaluating environmental and economic damage caused by the intensive development of coal industry, which allows for timely and effective action by authorities, is a pressing issue.

\section{Materials and Methods}

Coal mining industry, which includes numerous open pits, occupies large areas of land in the region [1] and "... is a source of negative environmental impact through air pollution and water contamination, contributing to the arable land degradation, including the storage of rock on them [4]". Coal mining in the region is increasing annually, which entails an increase in the alienation of agricultural, as a rule, highly fertile land. According to experts, mining of one million tons of coal requires an average of 10 hectares of land to be disturbed [11].

It should be emphasized that about 60 percent of coal in the region is mined using open cut methods. During the analyzed period (2013-2017), the area of disturbed land increased by 7.77 percent, from 73.3 thousand hectares to 79.1 thousand hectares [1]. The standard cost of the reclamation of nonfarm soils in 2014 was 1020 thousand rubles per hectare [2].

Underground coal mining is accompanied by the arrangement of sites for storing coal and rock, ventilation technology for underground workings, degassing, and contributes to the entry of methane into the atmosphere, which represents the main sources of air pollution. The stored rock contains significant amount of coal, and, when interacting with the atmosphere ignites spontaneously, releasing sulfur dioxide, resinous substances in the form of sublimation products, carbon monoxide.

Open cut mining technologies include blasting operations accompanied by gas-dusting, which is a pollutant of atmospheric air. High-intensity coal mining in the region, the consequences of a high degree urbanization are accompanied by signs of land degradation, including its fertility, a decrease in the animal population, and hence the loss of renewable natural resources. At the same time, the intensive coal mining industry development increases emissions of volatile substances into the atmosphere and pollutes the air. In 2017, the region ranks third in the Siberian Federal District in coal production, producing 241.5 million tons. Increasing volumes of coal mining are mainly accompanied by open air pollution. In 2017, pollutant emissions amounted to 1,487.6 thousand tons or 552.0 kilograms per inhabitant. Coal mining enterprises of the region emitted 8.8 percent more emissions in 2017 than in 2013.

There are more than 200 types of various substances that pollute the atmosphere. "Among them there are highly toxic and carcinogenic substances in the form of soot, lead, carbon oxides and nitrogen. The structure of pollutants to the greatest extent contains 
elements that are produced by stationary sources and are solids with a volume of 146.8 thousand tons. In addition, the volumes of gaseous and liquid substances occupy 1340.8 thousand tons" $[1,4]$.

An equally serious problem is methane and its emissions. The most promising way to solve this problem is to use methane for fuel, which will significantly reduce emissions of pollutants into the atmosphere.

Modern regional economic policy is aimed at the use of natural resource reserves, allowing the dynamic development of coal mining and metallurgical industries. From the point of view of the survival of the regional economy and the stable social activities, such development is fully justified. However, this does not solve the problem of improving health as one of the most important components of the quality of life, which is the main indicator of social and economic environment of the country and its individual regions.

The habitat and its quality is characterized by the health of the population, and the dynamics of the incidence of the working age population disease and mortality show the well-being and negative phenomena of regional development. The above mentioned indicators are the main problems for the Kemerovo region. Replacement of the population has a negative trend (Table 1).

Table 1. Replacement of the Kemerovo region population in 2013-2017.

\begin{tabular}{|l|c|c|c|c|c|}
\hline \multirow{2}{*}{\multicolumn{1}{|c|}{ Indicators }} & \multicolumn{5}{c|}{ Years } \\
\cline { 2 - 6 } & $\mathbf{2 0 1 3}$ & $\mathbf{2 0 1 4}$ & $\mathbf{2 0 1 5}$ & $\mathbf{2 0 1 6}$ & $\mathbf{2 0 1 7}$ \\
\hline $\begin{array}{l}\text { Population as at the beginning } \\
\text { of the year, thousand people }\end{array}$ & 2742.4 & 2734.1 & 2717.6 & 2708.8 & 2694.8 \\
\hline Birth rate (per mille) & 13.6 & 13.2 & 12.5 & 12.1 & 10.5 \\
\hline Death rate ((per mille) & 14.5 & 14.6 & 14.5 & 14.3 & 14.1 \\
\hline Infant mortality (per mille) & 7.3 & 7.2 & 6.7 & 7.3 & 6.9 \\
\hline $\begin{array}{l}\text { Natural population decline (per } \\
\text { mille) }\end{array}$ & -0.9 & -1.4 & -2.0 & -2.2 & -3.6 \\
\hline Life expectancy at birth, years & 67.7 & 67.85 & 68.31 & 68.72 & 69.33 \\
\hline
\end{tabular}

The population of the region in 2013-2017 decreased by 1.7 percent from 2,742.4 thousand to 2,694.8 thousand people. In the same period, the birth rate per mille decreased by 3.1 ( 23.9 percent). And although there was a positive trend in mortality and infant mortality, the demographics remain rather disappointing. The Kemerovo region has one of the highest population density rates among the regions of the Siberian Federal District, there are 28.15 people per square kilometer. At the same time, in the Siberian Federal District this rate amounts to 3.75, in the Russian Federation - 8.58 [3, 7-11].

As in the most regions of the country, the demographics can be characterized by a decrease in the population due to low life expectancy at birth and a decrease in migration growth. In 2017, 1,515 people less than in 2016 arrived to the Kemerovo region. The consequences of the negative impact of the negative environment on the demographics in the region are respiratory diseases, neoplasms, infectious and parasitic diseases, injuries, accidents at work and in everyday life.

The data of State Budgetary Healthcare Institution "KOMIATS" indicate a rise in the overall incidence of the population by 1.5 percent. In 2017, there is an excess of mortality over the birth rate of 9.8 thousand people, or 25.7 percent. Infant mortality (children under 1 year per mille) tends to decrease. 
However, it remains quite high due to the pregradient growth of diseases and a number of pathologies caused by the toxic effects of chemical compounds found in the air, water bodies and in general, the environment on the mother and fetus [3].

Summarizing the above, we can conclude that adverse environmental factors have a significant impact on health and, consequently, on the quality of life of the population, and there is no real improvement in the environmental profile.

\section{Methodology for evaluating environmental and economic damage to the Kemerovo Region economy}

The consequence of the negative impact of environmental factors on human health is underproduced GRP. Table 2 shows the cost of underproduction of GRP generated by the impact on water and air environment.

Table 2. Indicators for evaluating the damage resulting from the incidence of the population caused by environmental factors by groups of diseases, 2013-2017.

\begin{tabular}{|l|c|c|c|c|c|}
\hline \multirow{2}{*}{\multicolumn{1}{|c|}{ Indicators }} & \multicolumn{5}{c|}{ Years } \\
\cline { 2 - 6 } & $\mathbf{2 0 1 3}$ & $\mathbf{2 0 1 4}$ & $\mathbf{2 0 1 5}$ & $\mathbf{2 0 1 6}$ & $\mathbf{2 0 1 7}$ \\
\hline Population, thousand people & 2742.4 & 2734.1 & 2717.6 & 2708.8 & 2694.8 \\
\hline GRP, billion rubles & 668.3 & 752.0 & 843.3 & 865.3 & 10581.1 \\
\hline GRP, thousand /person/year & 243.7 & 275.5 & 309.9 & 318.9 & 391.6 \\
\hline Emission rate, thousand tons & 1356.0 & 1332.0 & 1344.5 & 1349.5 & 1487.6 \\
\hline Dirty discharge, million cubic meters & 598 & 478 & 462 & 444 & 433 \\
\hline The incidence of disease per mille & 1620.0 & 1576.0 & 1586.0 & 1596.0 & 1645.4 \\
\hline $\begin{array}{l}\text { Average annual number of man-days } \\
\text { lost due to illness }\end{array}$ & 15.0 & 14.8 & 12.6 & 12.7 & 12.7 \\
\hline $\begin{array}{l}\text { Cost of underproduction of GRP, } \\
\text { million rubles }\end{array}$ & 29712.7 & 30899.1 & 31084.5 & 31280.0 & 32249.7 \\
\hline GRP losses, \% & 4.4 & 4.1 & 3.7 & 3.6 & 3.4 \\
\hline
\end{tabular}

Calculated by the authors according to the data of Kemerovo Regional Medical Information and Analytical Center (State Budgetary Healthcare Institution "KOMIATS")

Table 2 reflects the cost of underproduced GRP generated by the incidence of the population, which suggests the rationale for developing automated tools (models, methods, algorithms) for analyzing this phenomenon.

\section{Results}

Currently, there are no advanced methodologies for evaluating environmental and economic damage to the economy caused by environmental factors, and the existing methods based on minimum and maximum levels of morbidity, mortality caused by their impact, the real state of affairs, in our opinion, do not fully reflect the real state [5].

In this study, the authors propose a method for evaluating environmental and economic damage to the regional economy (GRP loss) associated with the loss of working time due to morbidity, determined by the level of environmental pollution. This problem can be solved using the model of economic development of the region, the criterion of the efficiency of which is to maximize the cost of GRP, taking into account the interests of the producer, consumer and the tax center of the region, which include the environmental component.

Let's consider the following substantive statement of the problem of evaluating environmental and economic damage caused by the environmental component. 
The following economic agents operate in the region: producers $(\mathrm{P})$, consumers $(\mathrm{C})$, regional manager - tax center $(T)$. The producer $(P)$ organizes the release of the $n$-th number of product types, including innovative ones. It acquires (rents) basic production assets, buildings, land, etc., for the n-th number of enterprises of individual industries.

At the same time, the consumer $(\mathrm{C})$ is provided by the producer $(\mathrm{P})$ with funds for living in the form of wages, insurance contributions to social funds and spends them on his/her consumer spending (consumer basket) (CB). By collecting tax payments, fees, fines and realizing the redistribution of financial resources in the form of subsidies, the regional manager $(\mathrm{T})$ organizes the interaction between $(\mathrm{P})$ and $(\mathrm{C})$.

It is assumed that $(\mathrm{P})$ can produce products using environmentally dirty technologies, for which, according to certain rules, it is fined by $(\mathrm{T})$, increasing the financial resource at (T)'s disposal. As a result of exposure to pollutants, the (C) incidence rate increases, which leads to a loss of working time and, accordingly, an increase in production costs of $(\mathrm{P})$ for labor and, therefore, the cost of underproduced GRP.

It is required to determine the level of GRP losses associated with an increase in the (C) incidence, as well as the optimal investment in ОПФ (purchased equipment) and production (revenue from sales), which characterizes a regional economic development project, in which income and expenses (discount balance) of (P) and (C) and discounted tax flows of $(\mathrm{T})$ within the time bucket of $\mathrm{T}$ will take into account the interests and natural limitations of the activities of each of the economic agents to the maximum.

The setting of a mathematical problem includes the following notations: average cost of basic production assets - ck, k-th type, $\mathrm{k}=1, \ldots, \mathrm{n}$; average design capacity of basic production assets of $\mathrm{k}$-th type $-\mathrm{Vk}$; average operation time of basic production assets of $\mathrm{k}$ th type - Tk; costs per unit of k-th type - Pk; forecasted demand for k-th product type - qk; specific and maximum pollutant emissions per production unit of k-th type $-\xi \mathrm{k}$, Dk, respectively; amount of revenue $(\mathrm{P})$ from the sale of manufactured products $-\mathrm{R} ; \mathrm{Z}-$ total current (depreciation, wages, taxes, raw materials, materials, fines, etc.) costs (P); Am total depreciation charge; $\mathrm{S} 0$ - depreciable value of basic production assets; $\mathrm{Wb}$ - balance sheet profit $(\mathrm{P})$; $\mathrm{W}$ - net profit $(\mathrm{P})$; $\mathrm{C0}$ - initial fund $(\mathrm{C})$; I0 - maximum investment amount; value added tax (НДС); N1, N2, N3, N4, property tax (НИ), profits tax (НП), insurance contributions (CB) of enterprises (P); total environmental fines of enterprises; corresponding taxes and fees (rates) - $\alpha 1, \alpha 2, \alpha 3, \alpha 4 ; \alpha 5$ - penalty rate (expertly determined share of proceeds $(\mathrm{P})$ ); Dot1, Dot $2-(\mathrm{T})$ subsidies for $(\mathrm{P}),(\mathrm{C}) ; \beta$ (labour consumption) the share of total revenue from the sale of products of $(P)$ entering the wage fund; $p$ (consumption of materials) - share of total costs of $(\mathrm{P})$ used to purchase raw materials; $\mathrm{r}-$ discount rate, $\mathrm{T}$ - time bucket.

The balance equations of own funds of economic agents have the form:

$$
\begin{gathered}
\text { (P): } D P=W+A m+D o t_{1} ; \\
D C=C_{0}+\beta R+D o t_{2}-\sum_{k \in C B} q_{k} \\
(\mathrm{C}): \quad \\
(\mathrm{T}):
\end{gathered}
$$

\subsection{Conditions restricting the activities of regional economic agents}

The primary limitations are the solvency of producer and consumer: $\mathrm{DP} \geq 0, \mathrm{DC} \geq 0$.

The limitedness of investment and subsidies can be expressed as 


$$
\begin{gathered}
(\mathrm{P}): I \leq I_{0}, \\
(\mathrm{~T}): \sum_{i=1}^{2} \operatorname{Dot}_{i} \leq \operatorname{Dot}_{0} .
\end{gathered}
$$

Where, $(\mathrm{P})$ is the first condition limiting the maximum investment volumes, and the maximum amounts of subsidies received by agents $(\mathrm{P})$ and $(\mathrm{C})$ from the agent $(\mathrm{T})$ are the second limitation. The meaning of this task lies in the fact that the subsequent restrictions affecting the volume of production of each type of product in terms of value do not exceed the performance of ОПФ and the demand for it.

$(\mathrm{P}),(\mathrm{C})$ and $(\mathrm{T})$ performance criteria are:

$$
\begin{gathered}
J_{(\mathrm{P})}=T \cdot \frac{W+A m}{1+r_{\ni}}, \\
J_{(\mathrm{C})}=T \cdot \frac{\beta R}{1+r_{\ni}}, \\
J_{(\mathrm{T})}=T \cdot \frac{N_{1}+N_{2}+N_{3}+N_{4}+N_{5}}{1+r_{\ni}} .
\end{gathered}
$$

It should be noted that the specified performance criteria reflect a strategic (long-term) character, which manifests itself throughout the regional development time bucket, $r_{\ni}=\frac{r T}{1-(1+r)^{-T}}-1-$ static analogue of the project discount rate recalculated for the entire time bucket $T$.

Let's introduce the following variables: average value of $k$-th type $-x_{k} ; x_{n+k}-k$-th product type sales revenue $(k=1, \ldots, n) ; x_{2 n+1}=\operatorname{Dot}_{1}, x_{2 n+2}=\operatorname{Dot}_{2}, x_{2 n+3}=I$. Then $A m=\sum_{k=1}^{n} \frac{T}{T_{k}} x_{k}, R=\sum_{k=1}^{n} x_{n+k}-$ sales revenue for all products; $S^{0}=\sum_{k=1}^{n}\left(1-\frac{T}{T_{k}}\right) x_{k}$; $N_{2}=\alpha_{2} S^{0}$. Taking into account the introduced notations, the net profit (P) can be calculated by the formula $W=\left(1-\alpha_{3}\right)\left((1-p-\beta) R-A m-N_{1}-N_{2}-N_{4}-N_{5}\right) /(1-p)$, and the mathematical model of the problem to be solved will take the following form:

$$
\begin{aligned}
& N P V_{(\mathrm{P})}=T \cdot \sum_{k=1}^{n} \frac{\left(-\gamma_{k}-1-r_{3}\right) x_{k}+\eta_{k} x_{n+k}}{1+r_{\ni}} \rightarrow \max , \\
& N P V_{(\mathrm{C})}=T \cdot \sum_{k=1}^{n} \frac{\beta\left(1+\alpha_{4}\right) x_{n+k}}{1+r_{\ni}} \rightarrow \max \\
& N P V_{(\mathrm{T})}=T \cdot \sum_{k=1}^{n} \frac{\sigma_{k} x_{k}+\tau_{k} x_{n+k}}{1+r_{\ni}} \rightarrow \max , \\
& \quad \sum_{k=1}^{n} \gamma_{k} x_{k}-\sum_{k=1}^{n} \eta_{k} x_{n+k}+x_{2 n+1} \leq 0, \\
& \beta \sum_{k=1}^{n} x_{n+k}+x_{2 n+2} \leq C_{0}-\sum_{k \in C B} q_{k}, \\
& \sum_{k=1}^{n} \sigma_{k} x_{k}+\sum_{k=1}^{n} \tau_{k} x_{n+k}+x_{2 n+1}+x_{2 n+2} \leq 0 \\
& x_{n+k} \leq q_{k}(k=1, \ldots, n), \\
& -\delta_{k} x_{k}+x_{n+k} \leq 0 \quad(k=1, \ldots, n),
\end{aligned}
$$




$$
\begin{gathered}
\sum_{k=1}^{n} x_{k} \leq I_{0}, \\
\sum_{k=1}^{2} x_{2 n+k} \leq \text { Dot }_{0}, \\
\alpha_{5} \xi_{k} \frac{x_{n+k}}{P_{k} V_{k}} \leq D_{k} \\
x_{k} \geq 0 \quad(k=1, \ldots, 2 n+3),
\end{gathered}
$$

where $\delta_{k}=\left(P_{k} V_{k}\right) / c_{k}-$ return on basic production assets of $k$-th type;

$$
\begin{gathered}
\gamma_{k}=-\frac{T}{T_{k}}+1+\frac{1-\alpha_{3}}{1-p}\left(\frac{T}{T_{k}}-\alpha_{1}+\alpha_{2}\left(1-\frac{T}{T_{k}}\right)\right) \\
\eta_{k}=\left(1-\alpha_{3}\right)\left(1-\frac{\beta+\alpha_{1}+\alpha_{4} \beta+\alpha_{5} \xi_{k}}{1-p}\right), \\
\sigma_{k}=\alpha_{1}-\alpha_{2}\left(1-\frac{T}{T_{k}}\right)+\frac{\alpha_{3}}{1-p}\left(\frac{T}{T_{k}}-\alpha_{1}+\alpha_{2}\left(1-\frac{T}{T_{k}}\right)\right) \\
\tau_{k}=-\alpha_{1}-\alpha_{3}+\alpha_{3} \frac{\beta+\alpha_{1}+\alpha_{4} \beta+\alpha_{5} \xi_{k}}{1-p}-\alpha_{4} \beta .
\end{gathered}
$$

The developed model (1) - (12) is a three-criterion linear programming problem. Its multi-criteria analysis is performed by bringing it to an equivalent single-criterion problem, which has a convex linear combination of criteria [5].

The model contains the most important (P), (C) and (T) activity limitations that impede them to operate in a crisis mode, which implies: ensuring solvency (4) - (6) of the mentioned economic agents; the amount of production based on their demand for it is formed [5], not allowing the risks of its overproduction.

Inequality (6), at the same time, can be interpreted as the efficient use of ОПФ, or the degree of scientific and technical progress. Conditions (9) and (10) are aimed at limiting the volume of investments and subsidies, which are financial resources circulating in the financial system. (11) limit emissions of pollutants to their maximum permissible values.

A feature of the model is its optimization nature, which allows identifying the economic potential of (P) activity. This is an important argument in favor of its use due to the fact that the current practice of compensating the damage caused by environmental pollution in the form of an environmental fine is focused on indicators of current accounting reports of enterprises, which are often underestimated in the interest of minimizing tax and environmental costs; performance indicators of enterprises being underreported. Using the objective, automated tools for determining the economic potential of $(\mathrm{P})$ can be the basis for the efficient management of the regional environmental policy in the interaction between $(\mathrm{P}),(\mathrm{C})$ and $(\mathrm{T})$. The next feature of the proposed model is its linear and statistical nature. This predetermines the use of the model as an efficient algorithm in the numerical analysis of the automated rationale for the adopted and approved decisions developed by the regional authorities for various aspects of economic development.

For example, using the proposed model, as the authors see, if there is an appropriate statistical base, it is possible to solve the problem of evaluating the impact of the environmental component not only on environmental and economic damage, characterized by GRP losses, but also on the quality of life of the population. Preliminary calculations performed using the bench-mark data by means of the package [5] showed the existence of a solution to the problem described by model (1) - (12). 


\section{Conclusion}

Summarizing the above, we can conclude that there is considerable environmental and economic damage to the economy of the region caused by the intensively developing coal mining industry. In addition, this circumstance entails a profile that is characterized by a high anthropogenic load and the level of the incidence of diseases, exceeding the average figure in Russia by more than 2 times. The cost estimate of damage caused by the development of coal mining industry in the region shows an increase in the form of GRP losses generated by the adverse effects of the environment on public health. As a result of the low life expectancy of the population and the state of health, the population of the region decreases, which is fraught with high economic risks not only at the present time, but also in the future.

Therefore, the primary task of the regional authorities, in our opinion, is the development and adoption of immediate decisions aimed at the use of automated, objective tools to evaluate and balance the costs of improving economic efficiency and preserving the environment of the region. The developed methodology solves the problem of evaluating the impact of environmental components not only on environmental and economic damage, characterized by GRP losses, but also on the quality of life of the population. In addition, the optimization nature of the model makes it possible to identify the economic potential of producers and the objective efficiency of enterprises, which will allow adequate compensation for the damage caused by environmental pollution.

The methodology for evaluating environmental and economic damage to a regional economy is universal, and can be used by state authorities in adjusting future programs for the region's social and economic development, and other regions having the similar economic development level.

\section{References}

1. S. Zhironkin, S. Demchenko, G. Kayachev, E. Taran, O. Zhironkina, E3S Web of Conferences, 105, 03008 (2019)

2. V.G. Mikhailov, N.N. Golofastova, T.V. Galanina, T.G. Koroleva, Ya.S. Mikhailova, IOP Conf. Ser.: Earth Environ. Sci., 50:1, 012038 (2017)

3. V.G. Mikhailov, T.V. Kiseleva, V.A. Karasev, G.S. Mikhailov, V.A. Skukin, IOP Conf. Ser.: Earth Environ. Sci., 66:1, 012008 (2017)

4. S. Zhironkin, M. Gasanov, G. Barysheva, K. Kolotov, O. Zhironkina, E3S Web Conf., 15, 03012 (2017)

5. A. Krechetov, A. Khoreshok, V. Blumenstein. E3S Web Conf., 21, 00001 (2017)

6. N. Kudrevatykh, T. Snegireva, A. Tselischeva, E3S Web Conf., 15, 04006 (2017)

7. P.D. Kosinskiy, V.V. Merkuryev, A.V. Medvedev, Coal in the 21st Century: Mining, Processing and Safety, 366 (2016)

8. N. Zaruba, N. Egorova, P. Kosinskij, E3S Web Conf., 15, 04003 (2017)

9. S. Kostyuk, N. Bedarev, O. Lyubimov, A. Shaikhislamov, E3S Web Conf., 21, 01002 (2017)

10. A. Krechetov, V. Blumenstein, E3S Web Conf., 15, 00001 (2017)

11. V. Trifonov, O. Loyko, D. Nesteruk, S. Zhironkin, E. Strekovtsova, AIP Conference Proceedings, 1800, 050009 (2017) 